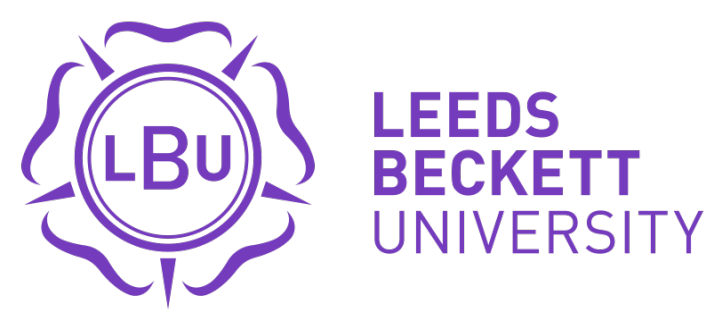

Citation:

Khosrowshahi, F (2015) Enhanced project brief: Structured approach to client-designer interface. Engineering, Construction and Architectural Management, 22 (5). 474 - 492. ISSN 0969-9988 DOI: https://doi.org/10.1108/ECAM-10-2014-0128

Link to Leeds Beckett Repository record:

https://eprints.leedsbeckett.ac.uk/id/eprint/2170/

Document Version:

Article (Updated Version)

The aim of the Leeds Beckett Repository is to provide open access to our research, as required by funder policies and permitted by publishers and copyright law.

The Leeds Beckett repository holds a wide range of publications, each of which has been checked for copyright and the relevant embargo period has been applied by the Research Services team.

We operate on a standard take-down policy. If you are the author or publisher of an output and you would like it removed from the repository, please contact us and we will investigate on a case-by-case basis.

Each thesis in the repository has been cleared where necessary by the author for third party copyright. If you would like a thesis to be removed from the repository or believe there is an issue with copyright, please contact us on openaccess@leedsbeckett.ac.uk and we will investigate on a case-by-case basis. 


\section{Enhanced Project Brief; Structured Approach to Client-Designer interface}

PURPOSE The focus of this work is on the client-designer interface where decisions have significant impact over the lifecycle of the project. Therefore, the briefing stage is examined in the context of clients' needs which is divided into project-based strategy and broader clients' strategy. The purpose of the work is to address the pitfalls in the briefing process which has been attributed to the shortcomings in the client-designer communication interfaces. This will be achieved by developing an automated brief generation framework. The research examines the efficiency of standard approaches to modelling and design, and the benefits that these methodologies have offered to the computer industry. The work reviews the similarities between the two industries and argues in support of the potential benefits in adopting a standard methodology in the construction industry. The structure upon which the framework is developed is based on System Analysis and Design Methodology (SSADM) which has proven to be an effective platform used within the software development industry.

\section{DESIGN / METHODOLOGY / APPROACH}

System Analysis and Design Methodology (SSADM) is an established methodology within the software development industry. The paper will demonstrate that due to fundamental similarities between the construction and software development industries, SSADM is likely to offer a viable platform upon which an automated enhanced brief generation model is developed for use in the construction industry. The construction design and construction process will be mapped on SSADM high level definition before focusing and honing on the design phase. The methodology for the development of the framework will be based on the rationalist approach of generating knowledge through reasoning leading to model-building.

\section{FINDINGS}

A model that is based on SSADM (System Analysis and Design Methodology) is proposed for the design development phase of construction projects. In order to shape the project strategy, the model considers the combined role of clients' requirements with organisation strategy and environmental factors. The paper has shown that it is feasible to increase the automation of the briefing process and enhanced the briefing output. The model here does not diminish the importance of direct communication between the client and the design team. It provides a more structured way of doing so, while taking advantage of vast array of data and technology in order to improve the brief outcome.

\section{PRACTICAL IMPLICATIONS}

There are several ways by which construction projects are procured. There may be fluctuation in their rate of usage, but while there is no indication of any procurement option fading, new ones such as PPP and PFI are periodically introduced. The existence of this diversity is indicative of the fact that the industry tends to respond to problems rather than attempting to instigate a measured solution supported by theoretical underpinning. Subsequently, there have been suggestions of a communication and information discourse between actors and within processes involved in project lifecycle. This project is aimed at addressing the gap in the client-designer communication. The 
automated approach to brief generation will lead to better briefs while reducing ambiguities as well as the overhead associated with brief generation.

\section{SOCIAL IMPLICATIONS}

The quality of project brief has a significant impact on decisions at the design stage. In turn, these decisions will influence all phases of construction project lifecycle. The briefing session and requirement analysis of a construction project can be very difficult for inexperienced clients particularly for complex projects. Therefore, there is potential for the process of clientrequirement-analysis to be optimised. The work promises to improve the quality of the briefing process, thus helping clients to realise their intended objectives and minimise resource waste.

\section{ORIGINALITY}

The work builds on the commonalities of the construction and software development industries and takes advantage of the advancements in the latter. In doing so, project quality is defined quantitatively which is used to develop project strategy in a three dimensional space. The development of the model was also contingent upon enhancement of Artificial Neural Network structure.

Keywords: SSADM, Artificial Intelligence, Project Strategy, Design Development. 


\section{INTRODUCTION}

It has been long recognised that the decisions at the design phase have significant impact on the building lifecycle and the operation costs over the life cycle are far greater than the sum of all other phases (Al Zarooni et al.. 2011). Design decisions also influence the space, quality of structural elements, technical/mechanical service equipment and material selection (Bogenstätter 2000). In turn, the design solution itself is overwhelmingly influenced by the outcome of the briefing exercise. However, there has been a clear indication of flaw in the communication between design and construction phases within construction projects (Chandra and Loosemore 2011a). This has raised the question about the effectiveness of the traditional role of the designer and the process of eliciting information during the briefing stage (Castell 2005). These issues have induced the need for the re-evaluation of the briefing process and its position within the overall design and construction phases. Historically, the weakest point at which discontinuities occur are at the client-designer and client-contractor interfaces (Hornet 1996, Chinyio, et al. 1999, and Castell, 2005). In particular there have been questions about the traditional role of the designer, lack of due consideration to life design solutions and the impact of design on buildability (Hansen and Vanegas 2003). It is envisaged this weakness is partially due to lack of an effective standardisation of the communication structure. While focusing on the healthcare projects in UAE, Al Zarooni et al. (2011), reiterate the importance of briefing for internal space planning, thus leading to more reliable cost estimating and facility plan. Similarly, Chandra and Loosemore (2011a) argue that increased interaction and communication exchange, and the subsequent knowledge exchange, will inevitably lead to better briefs. This is as the result of the development of common understanding through spontaneous social constructs. Chandra and Loosemore (2011b) also confirm that lack of interaction is a source of briefing pitfalls, because it results in the creation and enhancement of misunderstanding about the critical project objectives. They suggest that the briefing process needs to be organic and iterative so to attempt to minimise misunderstandings. Such considerations will also lead to less undesired variations. As Arian and Pheng (2005) argue, from 53 causes of variations, changes in plan or specification by the client, and safety considerations are amongst the most important causes.

The technology side of BIM provides a promising platform for a structured approach to management and communication of information across the supply chain throughout the project life cycle. Also, BIM as a collaborative paradigm provides a vision for the industry to work in a fully integrated environment. However, the successful implementation of collaborative BIM is contingent upon structured processes underpinned by established standards. This is an area which has seriously challenged the modern construction. On the other hand, computer science and information technology, which is relatively a new field of science, has demonstrated impressive appetite for development of standard methods for its various processes.

While there has been several research works towards improving the brief, there is little evidence of innovation beyond the traditional practice. The work by Hansen and Vanegas (2003) is amongst the few works that takes a radical view and proposes an automated approach to brief generation. They argue that the resulting benefits cover all phases of project lifecycle. Another innovation in developing a better brief is through exploration of visual representation for negotiating brief and design (Bendixen and Koch 2007).

The computing and IT industries and software development in particular, have experienced similar 
discontinuities. They have addressed these issues through the development of structured approaches to modelling the design and construction phases. To this end, the main focus has been on the standardisation of the communication between the client-designer and clientdeveloper. Several ad-hoc efforts culminated in a more orchestrated approach leading to the development of a series of structured methods entitled Structured System Analysis and Design Method (Ashworth and Slater 1992).

The parallel between the two industries highlights the potential for the adoption of the IT industry's structured approaches by the construction industry. This paper will examine the viability of the Structured System Analysis and Design Methodology with the view to its mapping on the construction design development phase. Subsequently, an automated brief generation framework is proposed. The work does not offer design solutions and does not undermine the importance of creative solutions. It aims to offer an improved understanding of the client's needs, thus helping the designer to develop better design solutions.

\section{CONSTRUCTION PROJECTS}

Construction projects have made significant uses of both hard and soft systems methodologies. A project is a system which aims to achieve specific objectives through congregation of human and nonhuman resources for a definitive period of time (Chekland, and Scholes 1990). It contributes to the success of a bigger system and its success is dependent on the success of its sub-subsystems. Project management has its origin in Systems Analysis and System Engineering which requires the setting of clear objectives and offering viable alternatives. The key role of the project manager is to direct managerial duties, co-ordinate and harmonise projects' legal, technical, and operational aspects, undertake effective supervision of resources, and align the goals of individuals with project objectives.

While there are numerous examples where operations research techniques are applied to various aspects of the management of all phases of construction projects, there is very little evidence to demonstrate a holistic appreciation of construction projects as a system. The majority of research works tend to focus on individual activities within construction operations or management, or with respect to individual systems engineering methods. There is clear lack of interest in viewing the project as a system and designing in accordance with systems approach. On the contrary, in the software engineering industry, several methodologies have been developed and applied to both the design as well as management of projects. An examination of the processes involved in the two industries reveals that there are many similarities that exist between the two.

\section{SOFTWARE AND CONSTRUCTION INDUSTRIES}

The proven success of the use of structured systems analysis and design methodologies in the software engineering has justified their consideration in construction industry, as both industries are in many ways comparable. In both cases, the main criteria for the success of the project are based on project time, cost and quality, and there exist a trade-off between these elements. In addition to the usual T-C-Q performance measures, there are similar narrative and normative measures such as the degree to which the goals of the project are achieved with respect to its 
operational and production objectives, as well as alignment with the organisational strategic goals. Below are some of the areas which highlight the potential adaptation of a software-based standard method by the construction industry.

- They have similar major players: the client, designer, contractor and sub-contractors.

- In both industries the Time, Cost and Quality are used as a measure of performance and success of the project

- Time and Cost are often used as a dominant for the selection of the contractor.

- In both industries, there are quality control measures and total quality management is applied. However, it is difficult to quantify and measure quality. Many research projects have attempted to address this issue but in practice, the examination of quality as a criterion for the selection of the contractor and project control has been somewhat subjective.

- In both cases a high volume of funds are involved and variations to the design can also be costly. There is reliance on financial control, regulatory compliances and auditing

- Medium to large-sized projects often require involvement of more than one contractor. This can hinder the communication between contractors and designer.

- Different data interchange standards in communication between designer and contractors may generate a misunderstanding in project details in both industries.

- In both industries, there may be many clients who are not fully aware of their real needs. However, there is an expert responsible to interpret and transform client's request to suitable format, which is understandable by the designer.

- The client can impose variations, which can alter project design.

- The environmental or human factors can produce changes in design and development.

- Both industries rely on reliability and security issues.

- They rely on extensive and systematic documentations and record keeping. They rely on support systems such as admin, accounting, personnel and management.Their production systems are similar: transforming raw material into a finished product.

Furthermore, the projects of the two industries are constrained by a number of common tactical issues: they have very little capacity for ambiguity and require clear statement of requirements, yet they operate under high level of uncertainty and require flexible design solutions in order to accommodate variations, they thrive on the integration and alignment of project-level and business-level specifications, and they are client-driven.

The similarities between the two industries are clearly evident from the above summation. There are off course a number of areas where the two industries differ. These include the comparative length of the maintenance phases; the nature of the end-users; the configuration and scope and complex nature of the supply chain. The two industries show dissimilarities in other ways such as the prolonged environmental and possibly social impact of construction products; diversity of procurement methods; and approaches to prototyping However, the similarities between the two industries have been examined within the context of the phases involved within the overall processes of converting an idea into a product.The paper addresses the shortcomings in the effectiveness of the communication between various participants in the construction project delivery process. The focus of the paper is on the client-designer communication that is formally recognised as the brief. To this end, the most pertinent parallel between the two industries relates to the phases involved in the process of converting an idea (or a need) into a final product and nurturing that product through its lifecycle all the way to the demolition (or 
decommissioning/un-installation). Typically, these consist of Feasibility, Analysis, Design, Implementation and Maintenance. Feasibility is dominated by financial, technical and social settings. The analysis is an information gathering exercise as well as specification requirement and constraint assessment, resulting in the production of the functional requirement specification. The design phase involves several stages leading to a number of solution alternatives and ending with a definitive design solution. At the end of the implementation/construction phase, a product/building is ready for trial-use before exploitation/occupation. During the maintenance phase, the system/building is in full operation and is in need of continuous attention. As with the case in the construction industry, the maintenance of software consumes the greatest portion of the resources - typically about $70 \%$ (Yeates et al. 1994 - p7).

\section{SYSTEM ANALYSIS AND DESIGN METHODOLOGIES}

Compared to construction, software industry is relatively a new industry, yet significant efforts have been directed towards standardisation leading to the development of several information systems methodologies supported by numerous standard techniques each addressing different aspects of the development. Since late 1970s, there have been a variety of design methodologies each armed with a set of analytical and implemental tools. There are currently over 400 Information Systems Development Methodologies in use. Below a few are introduced and one is adopted on the basis of its proximity to the processes related to construction projects.

YOURDON (Yourdon, 1988), is a pioneer in structure approach to systems development. The system optimises time by focusing on the 'essential model' and avoiding the complete modelling of the user's current system.

JACKSON System Development (Cameron 1988) is a UK-based system which complements the Jackson Structured Programming. It covers the complete development lifecycle from analysis to maintenance. However, the method contains some complex concepts.

LSDM - Learmoth \& Burchett Structured Development Method: consists of a set of prescriptive rules and has its techniques integrated into the overall method framework so the analyst/designer knows how the products of one stage or technique are used in the next stage. Its techniques include data modelling, data flow diagramming, entity life histories and process-outlines.

COMPACT: is another comprehensive package developed by Central Computer and Telecommunications Agency of the Civil Service, covered by Crown Copyright, with the aim of improving the operation of offices within central government.

Information Engineering (Palmer 1978): previously known as DDSS or D2S2 (Development of Data Sharing Systems) was developed by I.R. PALMER (London) in 1975. Enhancements took place in 1982 and 1983. It is an extension of structured analysis methods and has extended the support of the lifecycle by adding upstream information strategy planning and business analysis, and downstream implementation. As well as technical solutions, it offers a philosophy for information system management. But, its implementation is highly resource absorbent and the returns are not immediate. 
MERISE is a popular French method that was developed during early 1980s, for use mainly by public sectors, but widely used by commercial sectors. Its focus is on the development process entailed in developing information systems. It covers the whole lifecycle as well as the complete range of development processes such as master plan, preliminary study, detailed study, technical study, implementation and maintenance. The absence of English version of documentation is a hindrance to Merise’s universality.

EUROMETHOD (Turner and Jenkins, 1996), is a European Community scheme in order to harmonise existing methods into a greater and more applicable method.

SSADM: (Weaver etal. 1998), developed by the CCTA (Central Computer and Telecommunications Agency) in the early 1980's. It is an open system and was recently offered as a freely available de facto standard particularly in the UK government, but also in private sector and in other countries. SSADM is part of the family of structured analysis and design methods with some similarities with the systemic methods. It offers a software development lifecycle which covers feasibility study to physical design, supported by a set of techniques for analysing and designing data and processes.

Other systems include, DAFNE (DAta and Function Networking), AXIAL (Analyse et Conception de Systemes d'Information Assistes par Logiciels), HOOD (Hierarchical Object Oriented Design), LCM (Life Cycle Methodology of the German Mod), LCP/LCS (Logical Construction of Programs / Logical Construction of Systems), MEIN (MEtodologica INformatica), METHOD 1, NIAM (NIJSSEN Information Analysis Method). ORGWARE-M, RACINES, SADT (Structured Analysis and Design Technique), SA/SD (Structured Analysis / Structured Design), SETEC (SETec- Software Engineering Technology) and SDM (System Development Methodology).

\section{Structured Approaches to Analysis and Design - Parallel with Construction Processes}

A number of methodologies are introduced above. In this section a few popular methods are presented due to their proximity and relevance to construction processes.

A viable and recognised method is the Learmoth \& Burchett Structured Development Method (LSDM). This method makes use of Data Modelling, Data Flow Diagramming, Entity Life Histories and Process Outlines techniques (Parkin 1987). The main advantages of LSDM can be summarised as follows:

- A step by step approach to the use of each technique is provided using prescriptive rules where possible and comprehensive check lists and guidelines where necessary.

- The techniques are integrated into the overall method framework so the analyst/designer knows how the products of one stage or technique are used in the next stage.

- A comprehensive system of documentation aids helps ensure that system documentation is produced as an integral part of carrying out the development tasks, not as an optional afterthought.

An alternative approach is the COMPACT approach. COMPACT is a comprehensive package 
developed by Central Computer and Telecommunications Agency of the Civil Service, covered by Crown Copyright, with the aim of improving the operation of offices within central government (Cutts 1994).

By far, the most popular and recognised methodology is the Structured Systems Analysis and Design Methodology (SSADM) which is a structured method for design and development of new software products using predefined steps (Ashworth and Slater 1992). A key issue that gave rise to the development of SSADM is one of its core concepts relating to users' views and requirements. These inadequacies had been observed within the software development industry, as these requirements were frequently undermined by analyst and designers. These are also the aspirations that have been echoed by many construction experts and all major reviews by the government including Latham (1996), Egan (1998), Fairclough (2002) and Wolstenholme (2009). SSADM sets user-requirements at the forefront of its process. As the case is in construction, the user-requirement process should consider the fact that clients and users may not be experienced in the field of software development. Both industries tend to have a top-down approach to projects, typically starting with a "back of the envelop" before incrementally expanding to more granular levels. These developments are normally undertaken in three complementary perspectives: functionality or processes, data, and events (Yeates et al. 1994 p8). While the first two are relatively static, the latter is more dynamic, taking into account the impact of system behaviour over time. Basically, an information System is installed to execute organisations' data via its processes.

SSADM covers all phases of project lifecycle from strategy planning and feasibility to analysis, design, implementation and maintenance. However, the focus of this paper in on the design phase. The core of SSADM is shown in Figure 1, and expanded in Figure 2

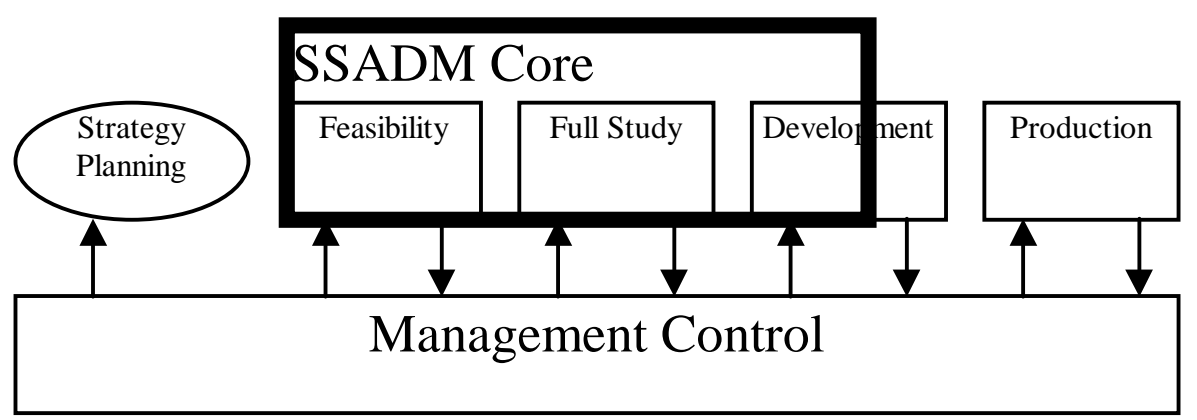

Figure 1, SSADM design and development phases.

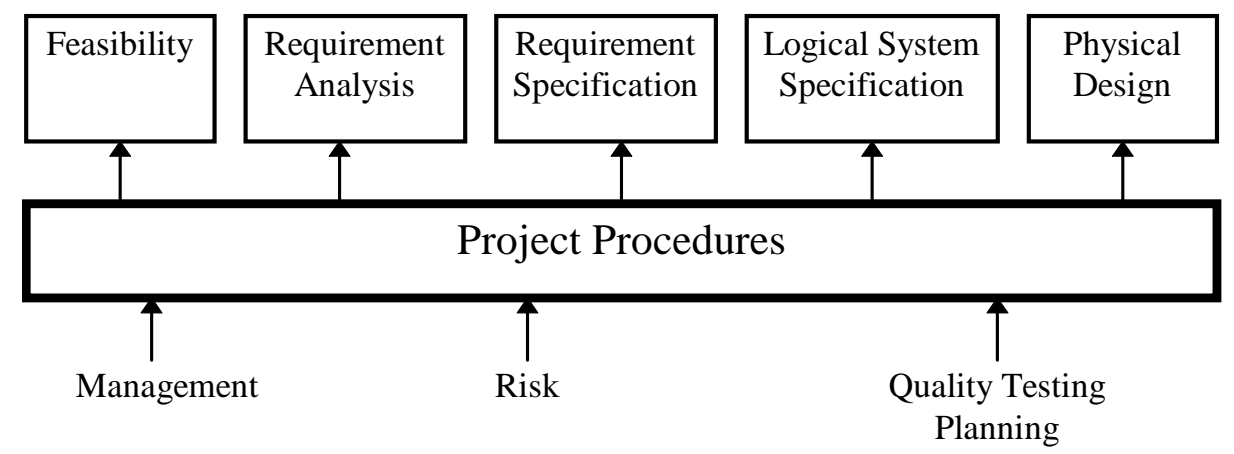


Figure 2, Detailed SSADM design phases.

In much the same way as project feasibility in construction, at the SSADM feasibility stage a high level view of the system is examined and after considering alternative options, one is identified as the way forward. In both industries, the requirement analysis stage looks at the needs of the client. One difference is that in computing industry a great deal of attention is given to the examination of the current system (for which SSADM has been criticised). This stage will also lay the foundation for the examination of options for business systems. The latter will lead to the development of the Requirement Specification, thus providing specifics of the proposed system (project). In some cases, there is also a Technical System Options stage that runs in parallel with Logical System Specification. Where applicable, at this stage alterative options (e.g hardware and software) are examined. However, there are cases where alternatives do not exist. In both domains project management is not an activity that is embedded in the stages but as a service to ensure effective delivery. The nature of the technical environment will impact on how the logical system design is transformed into a Physical Design.

Despite the similarities of the general phases of both industries, the use of SSADM in construction will require a minor consideration: In practice, the use of SSADM tends to apply a time overhead during early phases. In computing industry, this is alleviated through the use of Computer Aided Software Engineering (CASE) tools. In construction, similar tools can be used during the development phase of the design.

The examination of the characteristics of SSADM, LSDM, COMPACT and other design development methodologies has shown that SSADM has the structure and dynamism required for it to be applicable to the construction industry. The SSADM methodology has the right balance of sophistication and simplicity that is required for adoption for construction projects. This is also evident by the fact that SSADM is a de facto standard method and also popular amongst other industries such as manufacturing. Its generality enables easy adaptation by replacing certain steps with those applicable to construction projects. This is an advantage because the method is procurement-independent. SSADM offers '3-views' of an information system: data in the system, the events to which the system responds and the functions in the system, as perceived by the user (Yeates 1994 - p34). Finally, SSADM is an open system, thus requires no licence for its adoption and customisation. Its structure is logical and consists of five modules, seven stages and several steps and tasks. On the one hand this is considered as being too complicated while others use this comprehensiveness to their advantage for customisation.

Subsequently, the methodology adopted in this research is based on SSADM with the appropriate alterations. The latter consists of removal of irrelevant steps and addition of necessary steps, making the method suitable for processing in construction industry. Also, with minor alterations, the method can be applied to represent various situations. Therefore, in effect, the method is procurement-independent. However, the procurement method that is most suitable for use with this methodology is 'design and build', which offers dynamism in all phases of design and development.

\section{RESEARCH METHODOLOGY}


While the overall methodological platform is based on the SSADM, the methodology for conducting the research itself is based on a theoretical framework for the generation of an enhanced brief document. The methodological approach adopted here is in line with Plato and Descartes rationalist viewpoint that knowledge can be generated through reasoning, thus resulting in a theoretical solution. The approach here takes the view that "theoretical consciousness" can increase through examination of the fundamental assumptions about theorizing (Ritzer 1988). This could lead to an alternate framework for inquiry (Abrams \& Hogg 2004).

The work was conducted in several phases. Different parts of the model rely on independent theoretical and empirical research works that have been referenced respectively. Each of these works has had its independent research methodology. The proposed theoretical model needs to be tested against real-case scenarios. This task is a major separate undertaking that is outside the scope of this paper. However, parts of the project have been tested and fully described in separate publications. Examples include Learn-on-demand methodology and quantification of the Quality.

The proposed research offers a system for the generation of an enhanced brief in order to address the frequent miscommunication between designer and the client. The system is manifested through a framework which consists of a combination of components each requiring separate development methodologies. At the core of the framework lies the Strategy Making apparatus that relies on an interface with a knowledge-base engine as well as the use of an artificial intelligence enabled learning system. The embedment of the latter within the overall framework requires enhancement to the usual Neural Net structure, so to enable "teacher intervention" (Khosrowshahi 2011). Another key component of the strategy making system is the incorporation of the quality in a quantifiable manner. For construction projects, many of the requirements in a design brief are subjective and non-quantifiable. Within the typical cost-timequality space, these subjective requirements tend to fall under the quality variable. The development of the proposed strategy making system requires these variables to be represented quantitatively. This will allow generation of feasible solutions. These solutions need to be checked against rules and conditions in order to determine if they are acceptable otherwise, variations are introduced in an iterative process.

\section{HIGH LEVEL MODEL OVERVIEW}

In construction industry, the recognition of the benefits of the integration of design and production phases has resulted in the development alternative procurement routes that focus on a these phases. Dawood (1995) suggests development of an integrated bidding management expert framework, in order to produce a more systematic decision support system for the bidding process. Figure 3, broadly shows a high level overview of construction processes mapped on SSADM methodology, thus offering an integrated approach to design and production phases. 


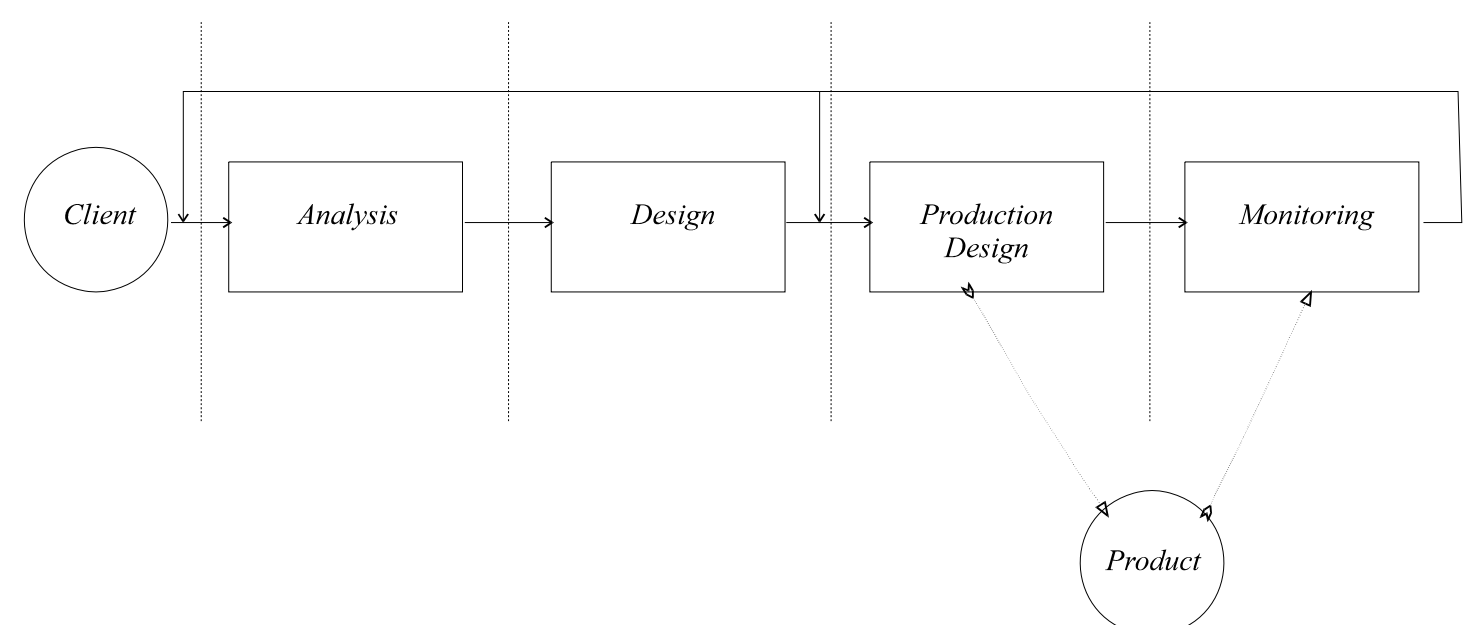

Figure 3, High level overview of model for construction projects based on SSADM

This process is detailed in Figure 4 which covers all stages relating to design development, production and monitoring as well as variations to the design.

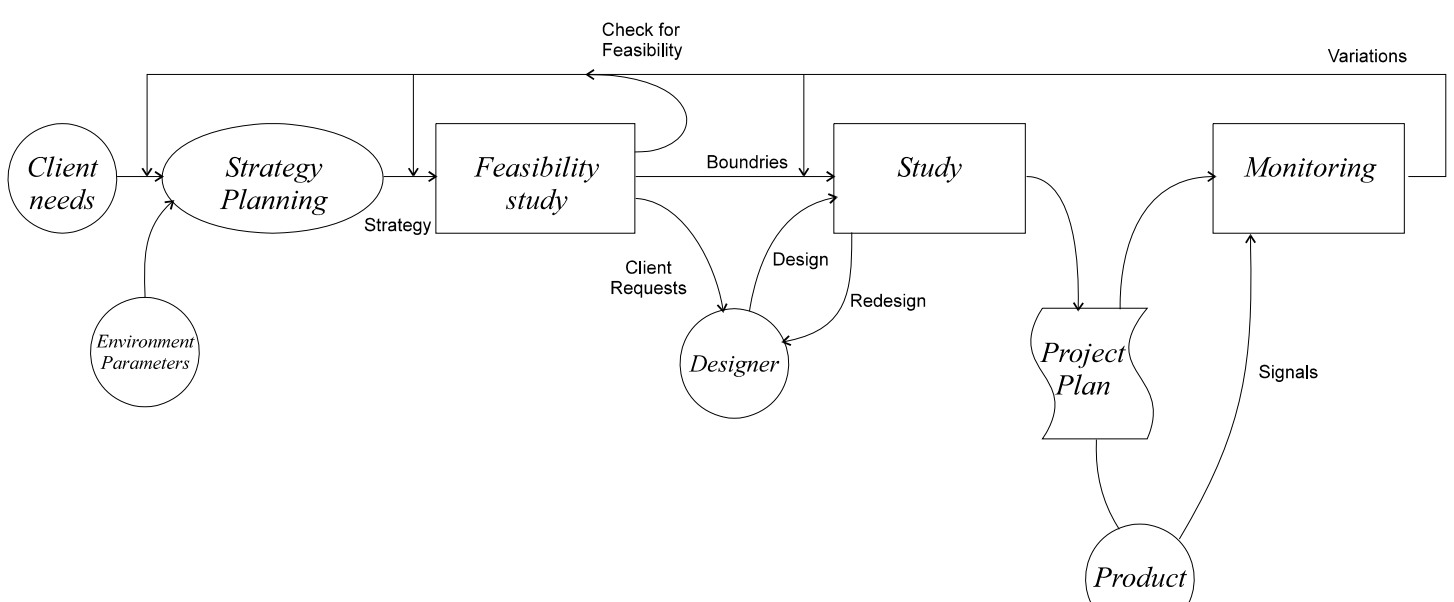

Figure 4, Detailed SSADM based model, adopted for construction projects.

The development of the overall system, which encompasses all phases of design development, production and maintenance, is a future programme which, is outside the scope of this paper. Here, the focus is on the client-designer interface.

\section{The Brief}

Baldry (1997) provides a detailed examination of the factors that impact on client's satisfaction and confidence in the industry. The brief in construction consists of all the activity conducted to evaluate the client needs clearly and completely, and the person who is responsible to do this job is the briefing engineer (Rwelamila and Hall 1995). Bogenstätter (2000) emphasises the importance of the decisions at the briefing stage and the need for an interdisciplinary team to ensure achievement of target values that emerge during the design process. There are different types of clients and they are categorised in a number of ways. The groupings include project type; project 
value, expertise or skill and size of organization history (Pryke and Smyth 2006). Worthington (1994) highlights the factors that influence clients' type and size on brief development. These factors include the experience of the client and project complexity. While focusing on Public clients, Alharthi et al. (2014) argue that clients' capabilities to undertake roles such as risk management, requirement management is a reflection of the way the project brief is developed. Clients also vary in terms of their business objectives: speculative clients have different priorities to those with sustainability agenda and with interest in lifecycle performance (Boyed and Chinyo 2006). Kamara et al. (2000) have examined clients' requirements within the concurrent engineering view of construction process. While recognising the variety of perspectives within clients' organisation, they propose a collaborative approach to developing the definition, analysis and translation of clients' requirements. This variety of perspectives includes those within the organization of the paying client (e.g. consortium or department); various user groups, and other stakeholders such as neighbourhood associations (Kamara et al. 1999). While recognising the importance of project definition, Fernie et al. (2003) question the notion that client requirement management is a new discipline within construction domain. Their assertion is supported by interviews that reveal discrepancies between the assertions in literature and what happens in practice. Chinyio et al. (1998) highlight the failure of the industry to meet clients' needs and use 'multi-dimensional scaling' and 'cluster analysis' techniques in order to offer an alternative methodology that promises to be more comprehensive. Subsequently, a bidding tool is proposed that matches client satisfaction to established project needs.

Other shortcomings associated with briefing practice are low involvement and intercommunication between relevant parties and those involved in briefing; inadequate time to briefing; low regards for the client's perspectives; and management of the changes to the brief (Kamara et al. 1999). The gap in the client-designer and client-contractor communication and the lack of study in this area are indications that the brief can be improved. The briefing session and requirement analysis of a construction project can be very difficult for inexperienced clients particularly for complex projects. Therefore, there is potential for the process of clientrequirement-analysis to be optimised. While criticising the effectiveness of briefing in construction, Castell (2005) argues that considerable improvement can be achieved through empowering the client and defining empowerment through its constituent qualities. Requirement engineering (capturing) is software industry's more systematic and structured equivalence of the briefing process in construction. The uptake of requirement engineering has received attention by many researchers in construction, but has hardly resulted in any practical use (Arayici et al. 2005). As part of broader project entitled DIVERSITY, these authors have taken an additional step by developing a prototype that promises an enhanced client briefing through a collaborative virtual design and brief environment.

The briefing process consists of two stages, each aiming at a different objective. At the first stage, clients' business objectives are examined whereas the second stage is a process of the conceptualisation of built solutions. An expanded view of design brief is offered by Jensen (2011) who argues that the brief is just as much about clients' aspiration as it is about their needs. He proposes an iterative approach to interaction with the client. Green (1999) suggests the use of Soft System Methodology to improve the strategic briefing which focuses on clients' business objectives. Collinge and Harty (2014) too assume a softer social view of the briefing process and propose an interpretation model for better understanding of the requirements. The model considers the role of sign-use interactions between the designer and the client. 
Strategic briefing is also examined by Bordass et al. (2001). They advocate improved performance through increased integration and reduced complication through emphasis on usability, manageability and minimizing downside risks. Laurell-Stenlund and Eriksson (2010) establish link between brief strategy and social aspects: while focusing on strategic aspects of public projects they examine the social implication of briefing in terms of cultural behavior of end-users. In doing so, they have identified factors such as 'space utilisation multifunctional design' that have positive impact as well those like 'visiting frequency' that do not. Another research focusing on the cultural aspects is by Loosemore and Chandra (2012). They propose that lack of iterative cultural learning at the briefing phase can lead to the loss of critical strategic information.

Often, for procurement methods, where design development is complete prior to the commencement of construction, variations to the design tend to have undesired cost and time implications. Also there is no evidence to suggest that the alternative forms of procurement, where a degree of concurrency exists between design and construction, offer an effective solution to the problem of client-request interpretation. Figure 5, provides an indication of complexity of the briefing phase in relation to the degree of client knowledge about construction and project complexity (Walker 1996).

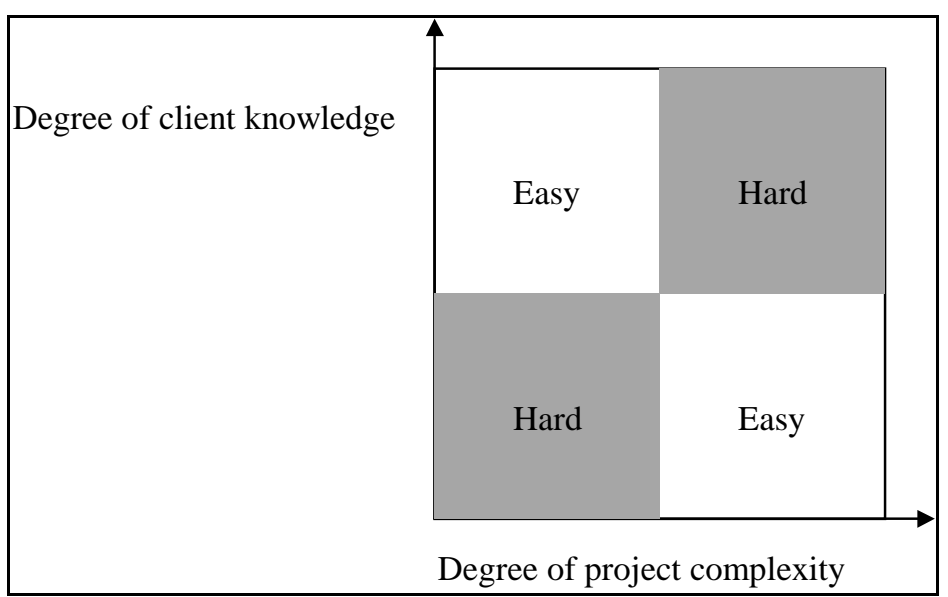

Figure 5, Complexity of briefing phase based on client knowledge and project complexityWalker, 1996.

\section{PROJECT STRATEGY MODEL}

A strategic view of the client's needs requires simultaneous consideration of several factors including social, economic and environmental. Any shortcomings arising from poor briefing impacts on the overall project-based strategic requirements of the client (Bordass and Leaman 1997). Generally, strategy is all the activities, functions, assumptions, rules and data that are involved in a particular decision which eventuates a program (BSI 1991). In construction, project strategy is influenced by several factors some of which are intrinsic to the project and others are external to it. The external factors include environmental issues (e.g. political), organisation's corporate strategy (e.g. growth) and corporate activities (e.g. financial management). The intrinsic factors are defined by project characteristics such as project definition, production specification, rules, boundaries, situations and variations. 
It stands to reason that the measure of success of project strategy is a measure of success of the project itself. It is widely accepted that project success is measured in terms of cost, time and quality (C-T-Q) performance. Also from the process model perspective, IAI -International Alliance for Interoperability- have recognised the client's need for a "plethora of information" all of which can be categorised under Cost, Time, Quality, Performance and Functionality headings (IAI 1999). It is recognised that for any given situation there can exist a trade-off between these variables, thus allowing some flexibility in reaching the final outcome. Also, there could be several final cost-time-quality outcomes that are acceptable to the population of clients with different needs.

Projects' C-T-Q are typically considered in a two dimensional space, measuring each pair at a time. However, due to the interdependence of these parameters the true measure of performance should be represented in a three-dimensional space. Basically, by defining the project, its boundaries, in relation to time, cost and quality will be identified. For any given project, there are many tactical paths through which a feasible C-T-Q outcome could be reached. Indeed, there can be infinite points on the 3D space where a combination of cost-time-quality satisfies the project strategy. These acceptable points can be confined into an area referred to as the 'acceptable space'. Equally, as shown in Figure 6, this acceptable space is referred to as project 'strategy space' where different strategy points can be visualised.

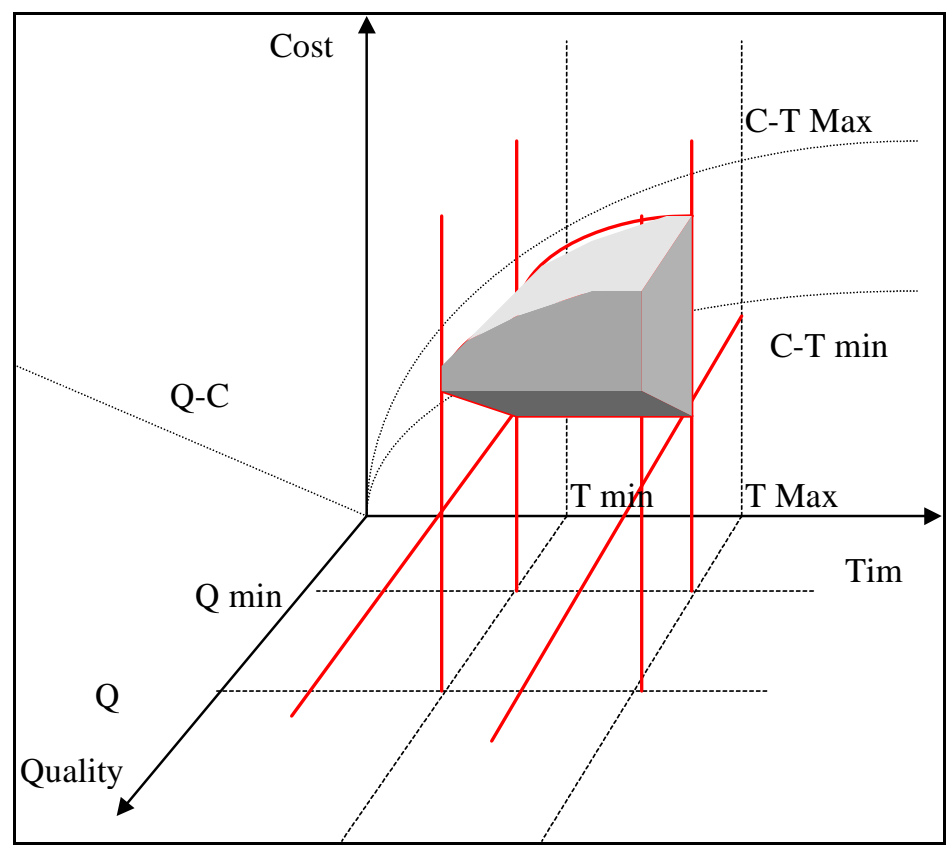

Figure 6, Strategy space in T-C-Q model.

From Figure 6, project commencement, represented by (to), initiates various paths that can be followed. Through the monitoring process, the project is continuously directed towards "acceptable solutions" within the strategic space. Each selected path, within start point to to end point $t_{\text {Max, }}$ results in the development of a series of tactical points leading to the identification of an optimum strategy point. So, for a given strategy, several tactical options are possible, as there exist many tactical variations. 
A major challenge for the development of a 3-D strategy space is the quantification of quality, as traditionally, quality is measured in a qualitative manner. The quantification of quality will allow quality to be traded against cost and time. According to Latham "value for money" encapsulates the definition of quality (Latham, 1996). This is articulated in BS4778-Section 2, Part 2:1991, Concept of Quality (BSI Part 2 1991) as follows:

I. The best fitness (fit for the purpose) for the given money.

II. The best Material Quality for the given money.

III. The most reliable design for the given money.

IV. The highest design durability allowance for the given money.

V. The best look or prestigious product for the given money

These definitions offer little in the way of quantifying quality. However, they have laid the foundation for Rad and Khosrowshahi (1998) to decompose them into several attributes specific to the perspectives of client, constructor and a third part view such as quality assurance companies or local authorities. They developed a quality quantification methodology by using a bidirectional ranking system of the importance level of quality attributes, based on the triangulation and statistical analysis of the data gathered from the three perspectives. They found that while the views from the three perspectives vary on individual attributes, their overall average claim on quality are similar.

\section{The Model Overview}

Figure 7 shows the proposed model for construction project design development which uses SSADM methodology as a base platform. The model incorporates strategic planning and feasibility study. The figure shows the role of organisation strategy and environmental factors in shaping project strategy development, before feasibility study is conducted. Here the client's request and strategic boundaries are identified and the design is iteratively produced. The solution consists of a number of stages. Initially, the model relies on the definition of the project which is influenced by client's needs and also external factors. Here, the client's needs should be classified, hence, RIBA's classification of building types is used (RIBA 1998).

The model contains the following two main components;

I- Strategy-making, which accommodates the strategic aspects of client's requests. Due to its nature, the artificial neural network is a most suitable technique to assist the strategy-making component. However, the training of the model requires the relevant data and also the learning process should cater for new situations not previously encountered by the model. To this end, the Learn-On-Demand methodology has been developed to facilitate enhanced learning (Khosrowshahi 2011).

II- Feasibility study, which examines whether, within the limits of predicted boundaries, the project is feasible to build. It also cross-checks project specification against a knowledge base.

Once project boundaries and tactics are produced by the strategy-making component, the feasibility study component examines the adjusted needs of the client. If, during this process, the feasibility requirements are violated, then project definition will be altered in order to make the project feasible. Subsequently, client's request specification is generated for the designer. As far 
as the feasibility study is concerned, knowledge-based learning methods is likely to offer a viable solution.

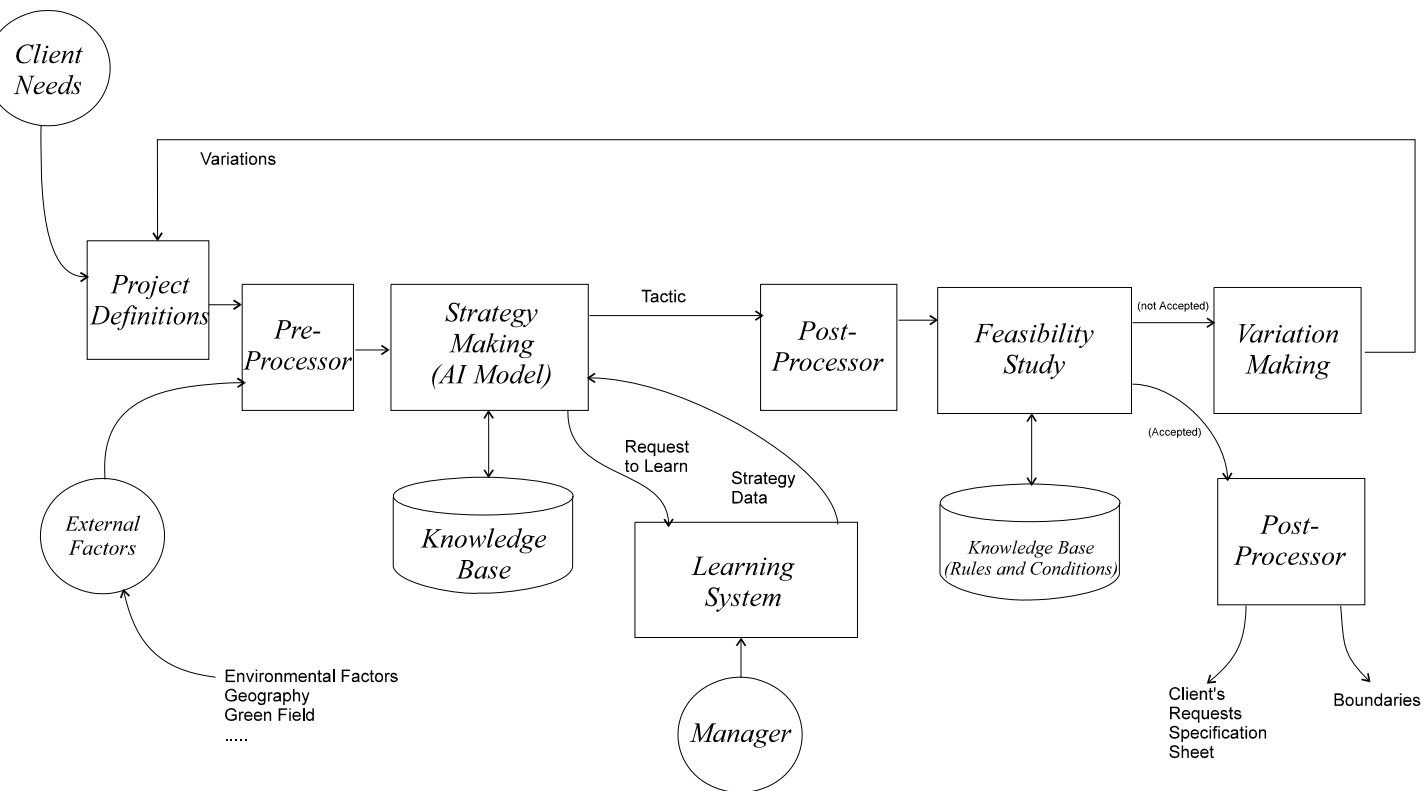

Figure 7, Design development system

As shown her and noted earlier, the focus of this work is on the client-designer interface and the model can be further expand to include all phases of design development and production

From practical perspective, the proposed framework is in its formative stage, thus requiring incremental refinement through several case studies. This is particularly true about the AI components of the system which typically rely on extensive data representing the real case scenarios. Therefore, the work invites further research into the examination of various parts as well as the overall system.

\section{CONCLUSION}

Having identified the need to improve the communication between client-designer and clientcontractor, the work established that the process by which this communication takes place needs to be revisited. Although the client-contractor interface is important and has significant impact on project performance, the focus of this paper is on the client - designer interface encapsulated in the breif process.The research drew a parallel between the software development and construction industries, and suggested that standard methods for analysis and design, adopted by the software industry, could be exploited by the construction industry. To this end, the research examined the suitability of a number of existing standard methods and concluded that SSADM provides a viable parallel for adoption by the construction industry. While the work applied SSADM to the overall design and production phases, the focus of the research was on the design development phase. The work aimed at developing a framework for the generation of an enhanced brief. Here, project strategy is shaped by incorporating such factors as client's needs, external factors and internal factors. The measure of success of the project strategy is based on the traditional measurement of project cost, time and quality. The proposed framework consists 
of a number of interlinked but independent components, each contributing to the production of the final outcome. The development of each component required a separate processes and methodology, but the overall methodology took a rationalist approach to the generation of knowledge through reasoning and theory-building. At the core of the framework lies the strategy making apparatus that generates a 3D space of acceptable solutions. The creation of this feasible space required quantification of quality. The strategy making system also relied on an interface with a knowledge-base engine and the use of a supervised neural net AI system. In order to mitigate the lack of relevant data, the architecture of the conventional ANNs was enhanced to allow intervention by a "teacher". The feasible solutions are then verified against rules and conditions through an iterative process involving an interface with a "rues \& conditions" knowledge-based system.

It is envisaged that the proposed framework has the potential to lay the foundation for improving the quality of brief which will in turn lead to better design, reduced waste and higher client satisfaction.

\section{REFERENCES}

Abrams, D., \& Hogg, M. A. (2004). Metatheory: Lessons from social identity research. Personality and Social Psychology Review. 8(2), 98-106.

Alharthi, A, Soetanto, R and Edum-Fotwe, F (2014) The changing role of the public client in construction procurement In: Raiden, A B and Aboagye-Nimo, E (Eds) Procs 30th Annual ARCOM Conference, 1-3 September 2014, Portsmouth, UK, Association of Researchers in Construction Management, 403-412.

Al Zarooni, S, Abdou, A and Lewis, J (2011) Improving the Client Briefing for UAE Public Healthcare Projects: Space Programming Guidelines. Architectural Engineering and Design Management, 7(4), 251-65.

Arian, F M and Pheng, L S (2005) How design consultants perceive potential causes of variation orders for institutional buildings in Singapore. Architectural Engineering and Design Management, 1(3), 181-96.

Arayici, Y, Aouad, G and Ahmed, V (2005) Requirements engineering for innovative integrated ICT systems for the construction industry. Construction Innovation: Information, Process, Management, 5(3), 179-200.

Ashworth,C. and Slater, L., (1992) An introduction to SSADM version 4, Mc Graw-Hill

Bendixen, $M$ and Koch, C (2007) Negotiating visualizations in briefing and design. Building Research \& Information, 35(1), 42-53.

Baldry, D (1997) The image of construction and its influence upon clients, participants, and consumers. In: Stephenson, P (Ed.), 13th Annual ARCOM Conference, 15-17 September 1997, King's College, Cambridge. Association of Researchers in Construction Management, Vol. 1, 52-61.Bogenstätter, U. (2000) Prediction and optimization of life-cycle costs in early design, Building Research and Information 28, no. 5 (2000): 376-386.

Bordass,W. and Leaman,A. (1997) Design for manageability. Building Research and Information 25, no. 3 (1997): 148-157.

Bordass,B., Leaman,A., and Ruyssevelt,P. (2001)"Assessing building performance in use 5: technical performance of the Probe buildings." Building Research and Information 29, no. 2 (2001): 144-157. 
Boyd, D. and Chinyio, E. (2006) Understanding the construction client. Oxford: Blackwell Publishing.

British Standards Institution, (1991) Quality concepts and related definitions, Quality Vocabulary, sec 4.1 (Part2, 1991)

Cameron, J. R. (1988) The modelling phase of JSD. Information and Software Technology. Vol. 30, No. 6. July/August. pp. 373-383.

Castell, L (2005) Empowering the client in the briefing process. In: Khosrowshahi, F (Ed.), Proceedings 21st Annual ARCOM Conference, 7-9 September 2005, London, UK. Association of Researchers in Construction Management, Vol. 1,

Chandra, V and Loosemore, M (2011) Communicating about organizational culture in the briefing process: case study of a hospital project. Construction Management and Economics, 29(3), 22331.

Chandra, V and Loosemore, M (2011) Sowing the seeds of misunderstanding in the briefing process: A case study of a new hospital project. In: Egbu, C and Lou, E C W (Eds.), Proceedings 27th Annual ARCOM Conference, 5-7 September 2011, Bristol, UK. Association of Researchers in Construction Management, 583-

Chekland, P. and Scholes, J. (1990) Soft Systems Methodology in Action, John Wiley, UK

Chinyio,E.A., Olomolaiye,P.O., Kometa,S.T., and Harris,F.C. (1998) A needs-based methodology for classifying construction clients and selecting contractors. Construction Management and Economics 16, no. 1 (1998): 91-98.

Collinge, W H and Harty, C F (2014) Stakeholder interpretations of design: semiotic insights into the briefing process. Construction Management and Economics, 32(7), 760-72.

Cutts G., (1994) Structured System Analysis and Design Methodology, Second Edition, Alfred Waller Limited, Henley-on-Thames, UK, 1994.

Dawood, N.N. (1995), An integrated bidding management expert system for the make-to-order precast industry, Construction Management and Economics, Vol. 13, pp. 115-125.

Green,S.D.(1999) A participative research strategy for propagating soft methodologies in value management practice. Construction Management and Economics 17, no. 3 (1999): 329-340.

Egan, J. (1998). Rethinking Construction. London: Report of the Construction Industry Task Force to the Deputy Prime Minister. Horner, R.M.W. (1996), Key Notes, ARCOM96, $12^{\text {th }}$ Annual Conference, Sheffield Hallam University, Sheffield, United Kingdom, 11-13 September.

Fairclough, J. (2002) Rethinking Construction. Lomdon: Construction Task Force

Fernie, S, Green, S D and Weller, S J (2003) Dilettantes, discipline and discourse: requirements management for construction. Engineering, Construction and Architectural Management, 10(5), 354-67.

Hansen, K L and Vanegas, J A (2003) Improving design quality through briefing automation. Building Research \& Information, 31(5), 379-86.

IAI UK (1999) Client Briefing Domain Committee Charter; http://www.iai.org.uk/cbdchart.htm, CCIT Admin 29 October 1999

Jensen, P A (2011) Inclusive briefing and user involvement: case study of a media centre in Denmark. Architectural Engineering and Design Management, 7(1), 38-49.Kamara, J M, Anumba, C J and Hobbs, B (1999) From briefing to client requirements processing. In: Hughes, W (Ed.), 15th Annual ARCOM Conference, 15-17 September 1999, Liverpool John Moores University. Association of Researchers in Construction Management, Vol. 1, 317-26.

Kamara, J M, Anumba, C J and Evbuomwan, N F O (2000) Establishing and processing client requirements-a key aspect of concurrent engineering in construction. Engineering, 
Construction and Architectural Management, 7(1), 15-28.

Khosrowshahi, F. (2011), Innovation in artificial neural network learning: Learn-On-Demand methodology, International Journal of Automation in Construction, Autom. Constr. AUTCON1267,PII S092658051100077X , doi: 10.1016/j.autcon.2011.05.004, vol 20 (2011), pp 1204-1210

Latham, M. (1996) Constructing the team. London: HSMO.

Laurell-Stenlund, K and Eriksson, P E (2010) Design factors' influence on value creation when building houses of culture. In: Egbu, C (Ed.), Proceedings 26th Annual ARCOM Conference, 68 September 2010, Leeds, UK. Association of Researchers in Construction Management, Vol. 2, 929-38.

Loosemore, $\mathrm{M}$ and Chandra, V (2012) Learning through briefing: for strategic facilities management in the health sector. Built Environment and Project Asset Management, 2(1), 10317.

Palmer, I. R., (1978) Practicalities in Applying a Formal Methodology to Data Analysis. Data Base Design Techniques I 1978: 147-171Pryke, S. and Smyth, H. (2006) The management of complex projects: a relationship approach. Oxford: Blackwell Publishing.

Parkin, Andrew, (1987) System Analysis, Second Edition, Edward Arnold publishing, NewYork,

Rad, H. N., and Khosrowshahi, F., (1998), Quality measurement in construction projects, Submitted to ARCOM'98 conference, Reading, $9^{\text {th }}-11^{\text {th }}$ September.

Ritzer, G. (1988). Sociological metatheory: A defense of a subfield by a delineation of its parameters. Sociological Theory, 6, 187-200.

Royal Institute of British Architects (1998) Classification of Building Types, RIBA Enterprises Ltd., www.ribabookshop.com

Rwelamila, P.D. and Hall, K.A. (1995), Total Systems Intervention: an integrated approach to time, cost and quality management, Construction Management and Economics, Vol. 13., pp. 235-241.

Turner P. and Jenkins T. (1996) Euromethod and Beyond, International Thomson Computer Press

Walker, A., (1996) Project Management in Construction, Blackwell Science, Third Edition, London, UK 1996, pp. 87-92

Weaver, P. L., Lambrou, N. and Walkley, M. (1998) Practical SSADM, $2^{\text {nd }}$ Ed. FT Pitman Publishing, London. ISBN 0273626752.

Wolstenholme_A. (2009) Never Waste a Good Crisis A review of progress since Rethinking Construction and thoughts for our future, Constructing Excellence.

Worthington, J. (1994) Effective project management results from establishing the optimum brief. Property Review. November. 182-185.Yeates, D., Shields, M. and Helmy, D. (1998) Systems Analysis and Design, Longman Group Ltd, Financial Times/Pitman Publishing, London.

Yourdon, E. (1988) Modern Structured Analysis, Prentice-Hall, Incorporated, ed.1. 